\section{One-Year Research Experience for Associate's Degree Students Impacts Graduation, STEM Retention, and Transfer Patterns}

\author{
Ron Nerio, ${ }^{\text {t* }}$ Althea Webber, ${ }^{*}$ Effie MacLachlan, ${ }^{\dagger}$ David Lopatto, ${ }^{5}$ \\ and Avrom J. Caplan ${ }^{\text {** }}$ \\ †Office of Research and ${ }^{\ddagger}$ Office of Research Evaluation and Program Support, City University of \\ New York, New York, NY 10017; "Center for Teaching, Learning and Assessment, Grinnell College, \\ Grinnell, IA 50112
}

\begin{abstract}
The CUNY Research Scholars Program (CRSP) provides a yearlong faculty-mentored research experience to associate's degree students. The program takes place at all 10 associate's degree-granting colleges within the City University of New York system. We report on a mixed-methods study of 500 students who participated in the program during its initial 3 years. Quantitative longitudinal assessments revealed that students who engaged in CRSP were more likely to be retained in a science, technology, engineering, and mathematics (STEM) discipline or to graduate with a STEM degree than their counterparts in a matched comparison group. Furthermore, students who participated in CRSP demonstrated an increased likelihood of transferring to the more research-intensive 4-year schools within the CUNY system and to R1 universities outside the CUNY system. CRSP students reported an increased sense of belonging in college based on survey data, and focus groups with their mentors provided insight into the factors that led to the gains listed above. These combined results-of student data analysis, student surveys, and mentor focus groups-provide evidence that early research experiences for associate's degree students contribute to their academic success.
\end{abstract}

\section{INTRODUCTION}

Undergraduate research experiences represent a gold standard for active learning, especially in the sciences. The impact of these experiences embodies both cognitive and noncognitive benefits for students. The cognitive benefits derive from a learning by doing approach, while the noncognitive effects range from increased self-confidence (Russell et al., 2007; Fechheimer et al., 2011) and self-efficacy (Carpi et al., 2016; Ritchie, 2016) to greater feelings of belonging in college (Wilson et al., 2015). The synergy between cognitive and noncognitive benefits makes undergraduate research a "high-impact" educational practice (Kuh, 2008). The results manifest in retention in science, technology, engineering, and mathematics (STEM) disciplines and increased rates of graduation (Rodenbusch et al., 2016).

Although there are 5.7 million students enrolled at 980 public community colleges nationwide, representing $41 \%$ of undergraduate students in the United States (American Association of Community Colleges, 2017; National Center for Education Statistics, 2017), most undergraduate research takes place at 4-year institutions. Community colleges focus more on teaching than research and have reduced institutional capacity to sustain a research infrastructure. Community college faculty also have higher teaching loads than their counterparts in 4-year schools (Brown et al., 2007). Research does take place at community colleges, however, and the Community College Undergraduate Research Initiative (CCURI) is one example of a large program
James Hewlett, Monitoring Editor Submitted Feb 22, 2019; Revised Mar 20, 2019; Accepted Mar 28, 2019

CBE Life Sci Educ June 1, 2019 18:ar25 DOI:10.1187/cbe.19-02-0042

*Address correspondence to: Avrom J. Caplan (avrom.caplan(acuny.edu) or Ron Nerio (ron.nerio@cuny.edu).

(c) 2019 R. Nerio et al. CBE-Life Sciences Education @ 2019 The American Society for Cell Biology. This article is distributed by The American Society for Cell Biology under license from the author(s). It is available to the public under an Attribution-Noncommercial-Share Alike 3.0 Unported Creative Commons License (http://creativecommons.org/licenses/ by-nc-sa/3.0)

"ASCB $®$ " and "The American Society for Cell Biology ${ }^{\prime}$ " are registered trademarks of The American Society for Cell Biology. 
that engages students in research experiences nationwide (Bock, 2018; Hewlett, 2018). The CCURI model involves both classroom-based undergraduate research experiences and faculty-mentored experiences.

At the City University of New York (CUNY), community college faculty are governed by the same employment contract that serves faculty at 4-year schools and are expected to engage in scholarly activities to attain tenure and promotion despite having a greater teaching load. This has led to the adoption of a research culture within the seven community colleges in the CUNY system (Caplan and MacLachlan, 2014) that is similar to the culture that exists in the system's eight 4-year schools and three comprehensive colleges (which offer both associate's and bachelor's degrees).

In this paper, we present the results of our assessment of a yearlong mentored undergraduate research experience in STEM fields for associate's degree students. The program, called the CUNY Research Scholars Program (CRSP), was established in 2014 and engages approximately 240 students per year. CRSP was started with funding from the Office of the Mayor of New York City as part of a larger investment in STEM programming at CUNY for associate's degree students. The CUNY Office of Research, located within the system offices for CUNY, designed the program for students enrolled in each of the seven CUNY community colleges and three comprehensive schools. The goal was to construct a decentralized program that enables each participating college to create its own localized programmatic identity around a set of uniform guidelines. The provost at each college appoints a campus-based CRSP director who recruits mentors and students and oversees programming for students. Program guidelines stipulate that students should receive approximately 400 hours of mentored STEM research experience over a yearlong period and that colleges should offer biweekly workshops on a variety of topics, including laboratory safety training, public speaking, library research, and scientific writing. To ensure individualized attention, the program administrators requested that faculty mentors be limited to no more than three students at a time; most mentor only one or two students. Students receive $\$ 5000$ stipends for participating in the yearlong program. The recruitment of students and faculty mentors was implemented at the college level to allow the CRSP directors to determine best practices for their campuses. Students broadly reflect CUNY's diversity: approximately 57\% were from underrepresented minority (URM) groups (i.e., Black and Latino). A small portion of the budget is set aside for administrative overhead for the campuses that usually pays for a director's summer salary or course release time.

Over the first 3 years of the program, the number of students enrolled grew from 143 to 234 due to an increase in funding. Likewise, the number of participating faculty also grew to 139 in the third year in the program, as compared with 86 in the first year. Each summer, the program culminates with a symposium in which all students present their work on posters and one student from each college gives an oral presentation. Student experiences were typical of apprentice-style faculty-mentored laboratory and field research.

Our study of the program's first 3 years (2014-2017) involved a quantitative longitudinal analysis of student outcomes data, surveys of students' views, and focus groups with faculty mentors. The goal was to determine whether 1-year research experiences for associate's degree students had a similar impact on student success as is found in programs at 4-year schools (Nagda et al., 1998; Lopatto, 2004, 2007; Russell et al., 2007). In addition, the study allowed us to examine the impact of the research experience on transfer patterns to baccalaureate programs and to understand what elements of the program were most important from the perspective of students and faculty mentors.

\section{METHODS}

This paper relies on multiple data sources. CRSP participation data were collected by program staff and transferred to the CUNY Office of Research, Evaluation, and Program Support. These data were linked to CUNY administrative data housed in the Institutional Research Database (IRDB) maintained by CUNY's Office of Institutional Research and Assessment and the National Student Clearinghouse (NSC). The research study including all surveys and focus group protocols was submitted to and approved by the CUNY Institutional Review Board (protocol number 2015-1076).

\section{Analysis of Objective Student Data}

Each cohort of CRSP students-year 1 (Y1; 2014-2015), year 2 (Y2; 2015-2016), and year 3 (Y3; 2016-2017)—was composed of a pool of students enrolled in one of the 10 participating CUNY colleges. Unique ID numbers assigned to each student allowed us to flag the records for CRSP participants in the institutional databases. The analytic data set included student-level information such as demographic characteristics (e.g., gender, race/ethnicity, age), enrollment features (e.g., college, class standing, full-time/part-time status), and academic background and standing (e.g, high school grade point average [GPA], cumulative credits earned, initial remedial status). Approximately $12 \%$ of students were excluded from the study because they fell outside the mandated student profile: they were enrolled in non-degree programs or bachelor's degree programs. Such students were enrolled in CRSP by mistake. In total, 556 students participated in CRSP between the 2014 and 2017 academic years, and 490 had records in the analytic data set. For students who participated in CRSP for more than 1 year, the record for the first year of participation was retained.

We employed propensity score matching (PSM) to identify a comparison group of individuals similar to the treatment group (Rosenbaum and Rubin, 1983). The propensity score is the estimated probability of a student receiving treatment conditional on all observable covariates. By matching students on the propensity score, leaving no statistically significant differences across characteristics, a reduction in bias may be achieved (Rosenbaum and Rubin, 1983; Dehejia and Wahba, 2002).

In creating a matched group, the goal was to achieve the highest level of balance between treated and "comparison" groups across observable characteristics, while retaining the highest number of observations (King et al., 2011). Students were matched using the demographic, enrollment, and academic variables in the analytic data set. To account for differences in the likelihood of participating in CRSP over the 3 years, we ran each match within the academic year. Furthermore, CRSP participants were force-matched (exactly matched) within college and by class standing (i.e., freshman, sophomore). The matching process benefited from the large 
number of potential comparison students. Because there was an abundance of possible matches, the risks associated with matching specifications (e.g., selection order, caliper choice) were diminished (Lunt, 2014).

CRSP participants from years 1-3 were matched using a one-to-one match without replacement with a caliper restriction of 0.001 (or 0.25 SDs) and assigned matches in descending order of propensity score (Cochran and Rubin, 1973; Rosenbaum and Rubin, 1985; Lunt, 2014). After matching, there remained no significant differences between CRSP students and comparison students, and the sample retention rate was $100 \%$.

Using the CRSP and matched cohort ID numbers, we obtained full records for students in both groups from the CUNY IRDB. IRDB records provide comprehensive data for all students, including selected majors, course enrollment, GPA for each semester, cumulative GPA, college of enrollment, date of graduation, and transfer within CUNY. To track transfer external to CUNY, we accessed student data through the NSC. For dichotomous variables, such as STEM retention and degree completion, we calculated percentages and measured differences using Fischer's exact test, setting the significance level at 0.05 .

\section{Surveys and Focus Groups}

We complemented our analysis of objective outcomes with surveys and focus groups. Our initial assessment used a wellknown survey instrument called the Summer Undergraduate Research Experience survey (SURE III). The survey addresses how students perceive their own learning gains using a pre(pre-flection) and postexperience instrument (Lopatto, 2004, 2007; Lopatto et al., 2008).

The SURE survey (modified slightly to be more suitable for community college students; for example, asking about transfer to a baccalaureate program as a next step) was administered online to Y1 and Y2 CRSP students, and we received a combined response of 93 for the pre-flection survey and 94 for the postexperience survey (overall response rate of 29\%). We did not administer this survey to the comparison group students, as it was designed specifically for students who undertake a research experience. Instead, the CRSP student responses were compared with those from students from other programs across the United States who also took this survey in $2017(n=2252)$.

Though suggestive of higher learning gains, our administration of the online SURE survey resulted in a relatively low response rate. Therefore, during the program's third year, we designed a survey specifically tailored for CRSP students who participate in a full-year program. To ensure a higher response rate, we distributed a paper copy of the survey at the symposium on July 25,2017 , the only occasion during which students from all 10 colleges gather together in the same space. We advised students that the survey was anonymous, participation was optional, and their decision whether or not to complete the survey would not affect any other aspect of their participation in the program. Of the estimated 236 students present at the symposium, 124 (53\%) completed the questionnaire. A copy of the survey is presented in the Supplemental Material.

The survey was a retrospective instrument that asked students to consider their experiences after completing a full year in the program and to compare their time in CRSP with their experiences as students before entry into the program. The
CRSP survey contained sets of questions that covered a range of topics, including: how respondents were recruited into the program; how respondents viewed themselves before entry into the program; how students viewed their college experiences before entry into the program; and how CRSP affected their course work, their college experiences, their level of involvement in college outside of CRSP, and their sense of self-confidence. We also asked students to tell us how they believed each part of the CRSP structure-the stipend, college-based programming, the mentors-affected their experiences. Finally, we asked students how external employment affected their participation in the program and whether the stipend enabled them to reduce their work hours.

During Y3 (2016-2017), we held face-to-face focus groups with mentors at six of the 10 colleges and conducted interviews with the CRSP program directors at each of the same colleges. We invited only mentors who had participated in at least one full year in the program, and many of those who accepted our invitation had participated during all 3 years of the program's existence. Both mentors and directors were advised that participation in focus groups or interviews was voluntary and would have no impact on any other aspect of their participation in the program. They were also told that neither their names nor identifying information, including their college names, would be used in any written materials related to focus group reports; therefore, in our notes, we identified each college with a pseudonymous letter (i.e., College A, College B, etc.). So that mentors could speak freely, the directors were not present during mentor focus groups. A total of 33 mentors chose to participate, comprising $26 \%$ of the total number of Y3 CRSP mentors. R.N. and A.J.C. conducted the focus groups; A.J.C. was present during four of the focus groups, and R.N. for all six.

We developed a list of open-ended questions for mentors, but encouraged participants to share any ideas, concerns, or perceptions about the program. We opened each focus group by asking mentors to tell us how their participation in the program had affected them personally and professionally. Such questions are vital for formative assessment, as the program depends on the continued goodwill and enthusiasm of faculty.

In our next question, we sought to understand how mentors viewed their role, including the ways in which they balanced various program aspects and potential obligations: guiding students in laboratory or field settings, serving as scientific and scholarly role models, acting as academic advisors, and providing personal support for students. Our final, and most extensive, set of questions asked mentors to share their perceptions of the impact of the program on students, including any ways in which the program might benefit from change or improvement. We preceded or followed all mentor focus groups by interviewing college-based directors, who shared the own perceptions of the program's impact and of the role that faculty members played in mentoring their students.

\section{RESULTS}

Over the first 3 years, 556 students were enrolled in CRSP (see Supplemental Table S1 for the distribution of students across the 10 participating schools). Our longitudinal analysis is based on 490 students identified in the IRDB (see Methods). Based on an analysis of abstracts at the student summer symposium, 33\% of the students were engaged in biological sciences, with 
TABLE 1. Graduation of students in the CRSP and comparisons groups

\begin{tabular}{lccc}
\hline & $\boldsymbol{N}($ Y123) & Graduated & $\%$ \\
\hline CRSP & 490 & 289 & $59.0 *$ \\
Comparison & 490 & 246 & 50.2 \\
\hline$* p=0.007$. & &
\end{tabular}

TABLE 2. Graduation of CRSP and comparison groups by gender

\begin{tabular}{lccc}
\hline & Graduated & Female & Male \\
\hline CRSP & 289 & 146 & 143 \\
Comparison & 246 & 130 & 116 \\
\hline
\end{tabular}

approximately equal numbers of students engaged in research in environmental sciences (15\%), chemistry (14\%), and social sciences $(13 \%)$. The remainder engaged in research in engineering (10\%), physics (8\%), math $(3 \%)$, and computer science $(5 \%)$.

\section{Impact of CRSP on Graduation and STEM Retention}

We first measured graduation among the CRSP and comparison groups from the first three cohorts (Y1, Y2, and Y3), which included students who finished the program in the Summer of 2015, 2016, and 2017, respectively. Our findings, shown in Table 1, show that students who participated in CRSP are significantly more likely to graduate than their counterparts in the comparison group (59 vs. 50.2\%; $p=0.007$ ), despite having a similar average number of academic credits when the program began (34 credits) and a similar average number after 1 year (55 credits). Most CRSP students graduated with an associate's degree, as expected; the number of baccalaureate degrees awarded was $5.2 \%$, with $4.4 \%$ of the comparison group students awarded a baccalaureate degree.

Further analysis of graduation patterns investigated the breakdown by ethnicity, gender, and major. Similar numbers of female and male students graduated from CRSP (Table 2), although male students from the comparison group graduated at lower rates than female students in that group $(p=0.048)$. When graduation data were filtered by ethnicity, we observed little difference between the CRSP and comparison groups for Asian, Black or Latino students (Table 3), although white students from the comparison group were significantly less likely to graduate than their counterparts in the treatment group.

Analysis of graduation patterns by discipline revealed several significant differences between CRSP and comparison group students (Figure 1). CRSP students were significantly more likely to graduate in a STEM discipline, especially in gen- eral science, biology, chemistry, and engineering. In contrast, comparison group students were significantly more likely to graduate in non-STEM disciplines. One exception to this trend was that comparison group students were more likely to graduate with a computer science degree than CRSP students. This pattern among computer science graduates occurred across several schools that participated in the program and therefore represents a general trend rather than a specific function of the program at one school.

We next investigated STEM retention independent of graduation. For this analysis, we investigated each cohort separately and examined whether the students were in a declared STEM major 17 months after beginning the program (at the beginning of the Winter/Spring semester of the following academic year). The timeline was chosen to give students one semester to settle in if they transferred to a senior college. We first analyzed the relative distribution of CRSP and comparison group students in declared STEM disciplines at the beginning of the program (Figure 2A), when the proportions were nearly identical for both groups (approximately 80\% in declared STEM disciplines) as a result of the PSM algorithm. Seventeen months later, $67 \%$ of CRSP students and $63 \%$ of comparison group students were still at CUNY, and of these, significantly more were retained in STEM if they had gone through CRSP (Figure 2B). These combined findings indicate that participation in CRSP promotes STEM retention and increases the likelihood that students will graduate in a STEM discipline.

\section{Impact of CRSP on Student Transfer Patterns}

Most CUNY community college students who transfer to another college enroll in a CUNY 4-year school. Eleven 4-year schools in the system (including the comprehensive colleges) are distributed among the five boroughs of New York City.

We tracked whether participation in CRSP at a community college had any impact on subsequent school choice after transfer. We calculated that $50 \%$ of CRSP students and $43 \%$ of comparison group students from community colleges transferred to a CUNY 4-year college the semester following the end of the program. Because students at comprehensive colleges usually continue in the same college when they switch from associate's to bachelor's degree programs, we did not include the comprehensive colleges in this portion of our assessment.

Of the CRSP students who transferred from community colleges to CUNY 4-year schools, more than half went to the City College of New York (CCNY) and Hunter College as compared with $31 \%$ of comparison group students, who were more evenly distributed among all of the 4-year colleges (Figure 3). The difference between the number of CRSP and comparison group students who enroll at CCNY and Hunter is significant; it is also

TABLE 3. Graduation of CRSP and comparison groups by ethnicity

\begin{tabular}{|c|c|c|c|c|c|c|}
\hline Ethnicity & CRSP total & CRSP graduation & CRSP \% graduation & Comparison total & Comparison graduation & $\begin{array}{c}\text { Comparison } \\
\% \text { graduation }\end{array}$ \\
\hline Total & 490 & 289 & 59 & 490 & 246 & 50 \\
\hline Asian & 113 & 64 & 57 & 107 & 53 & 45 \\
\hline Black & 158 & 87 & 55 & 165 & 90 & 55 \\
\hline Latino & 125 & 78 & 62 & 127 & 66 & 52 \\
\hline White & 94 & 60 & 64 & 86 & 37 & 43 \\
\hline
\end{tabular}




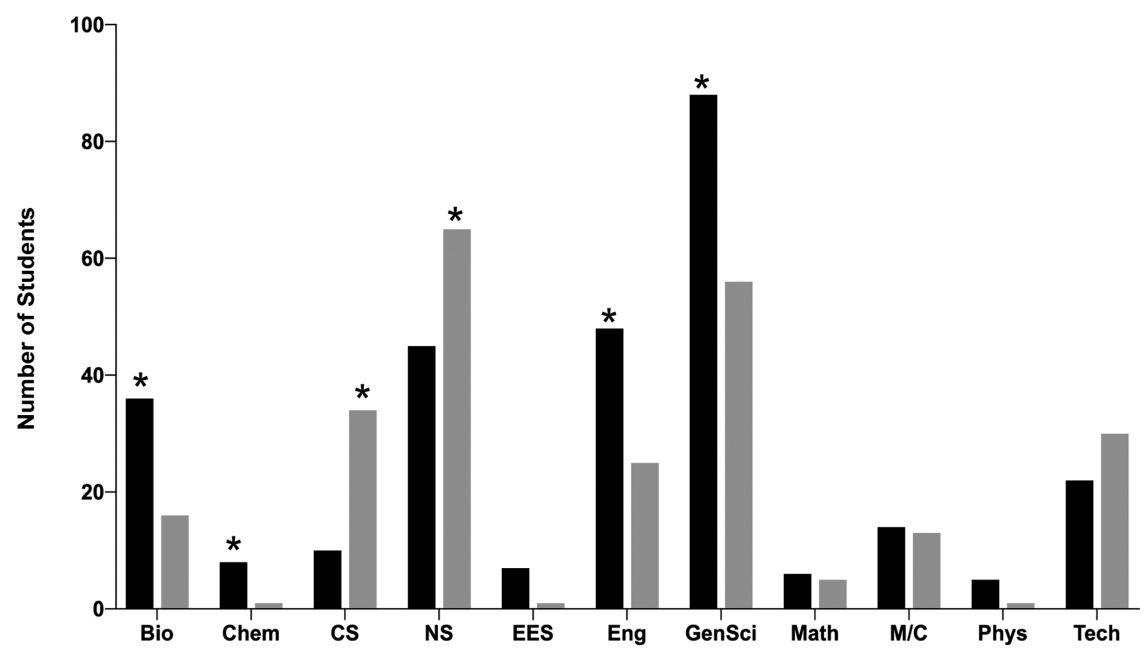

FIGURE 1. Graduation by discipline for CRSP and comparison group students. The CUNY institutional database was queried for the disciplines of graduating students from the two groups (CRSP, dark gray bars; comparison group, light gray bars). Key: Bio, biology; Chem, chemistry; CS, computer science; NS, not STEM; includes humanities and social sciences; EES, environmental sciences; Eng, engineering; GenSci, general science; Math, mathematics; M/C, medical/clinical; not considered STEM; Phys, physics; Tech, technology. Statistical significance was calculated using Fisher's exact test, and an asterisk (*) denotes $p \leq 0.05$.

notable, because these two schools receive more than half of the total research funding for the entire university system (based on 2016 CUNY Research Foundation data) and, as such, stand out as the most research-active colleges in CUNY. To determine whether this trend of transferring to research-focused institutions also applied for students who transferred to schools outside the CUNY system, we queried all 490 students who began the program (plus all 490 comparison group students) through the NSC. We found that 77 CRSP students enrolled in colleges outside CUNY, and of these, 54 (70\%) went to schools designated R1 by Carnegie Classification. By contrast, 56 comparison group students attended schools outside CUNY, of whom 22 (39\%) went to R1 colleges ( $p=0.0007$, Fisher's exact test). These findings demonstrate that participation in CRSP influences college destination after transfer, resulting in higher rates of enrollment in colleges that are more research active, both within and outside the CUNY system.

\section{Surveys of Students}

To assess student learning gains during the CRSP experience, we administered the SURE III survey to Y1 and Y2 cohorts online (see Methods for details). SURE III is a well-known survey instrument that has been used by more than 1000 colleges nationwide (Lopatto, 2004, 2007; Lopatto et al., 2008). The self-reported gains, shown as a mean, made by the students across 21 learning gains are presented in Figure 4. In all cases, the CRSP students' self-reported learning gains were greater than the national average, with the most marked differences including "skill in how to give an effective oral presentation," "skill in science writing," and "self-confidence." It is likely that the higher learning gains for CRSP students compared with others in the national sample are due to the fact CRSP is a yearlong program, and the SURE survey is generally administered to stu- dents who complete a summer research experience.

In the Y3 CRSP survey, we were particularly interested in understanding how the program affected students' sense of belonging in college. One-third (33\%) of students responded that they enjoyed attending college before participating in the program, but nearly two-thirds (65\%) stated that they enjoyed going to college after entry in the program. Less than onethird $(27 \%)$ of respondents told us they "felt comfortable" or "at home" in their college before entering the program, but nearly two-thirds (64\%) felt so after participating in CRSP.

Fully two-thirds (66\%) reported that, before involvement in CRSP, "college consisted of going to classes, with little other involvement" beyond course work, and only one-third (33\%) of the students reported that they felt someone at their college cared about them. However, 59\% reported feeling more connected to their college after participating in the program and the perception of being cared for nearly doubled to $65 \%$.

Students attributed considerable positive influence to their mentors. Fully $85 \%$ of students responded that their mentors helped them develop scientific skills and knowledge. Nearly three-quarters $(72 \%)$ responded that their mentors genuinely cared about them as individuals. Almost two-thirds (62\%) believed their mentors contributed to their increased sense of self-confidence.

The program centers on research external to the classroom and appears to have had a mixed impact on course work. Twenty-nine percent of students told us that they felt the program helped them participate more in class, while 34\% believed it led them to concentrate more on course work. A higher percentage (43\%) told us that CRSP had made them feel more enthusiastic about their course work. These numbers suggest that there is some positive impact on in-class performance but it is not as strong as the impact on overall sense of student belonging in college.

One of our ongoing concerns has been the degree to which outside paid employment affected students' ability to successfully participate in the program and to balance the demands of the program with course work requirements. CRSP encourages students to engage in outside work as little as possible during the academic year, and especially during the summer, when the research experience is at its most intense. Most students (67\%) responded that they did participate in non-CRSP employment during the program. Nearly one-quarter (24\%) indicated that they worked more than 15 hours per week during part, or all, of the program's duration and a similar proportion (23\%) were employed during the summer, when the program requires them to spend as many as 30 hours per week in the laboratory.

Fifty-nine percent of those who had jobs indicated that outside employment made it more difficult for them to concentrate on CRSP and classroom work. Twenty-five percent said that the 


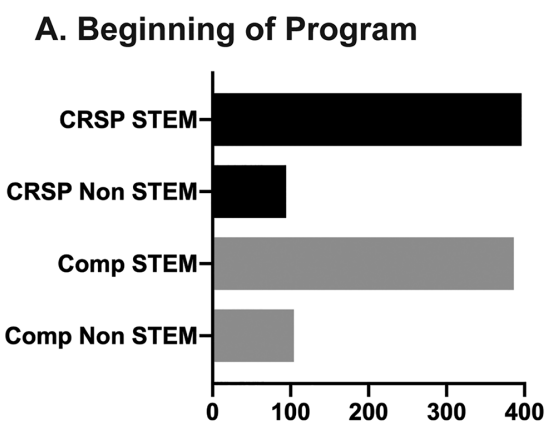

Total number of Students (2014-2017)

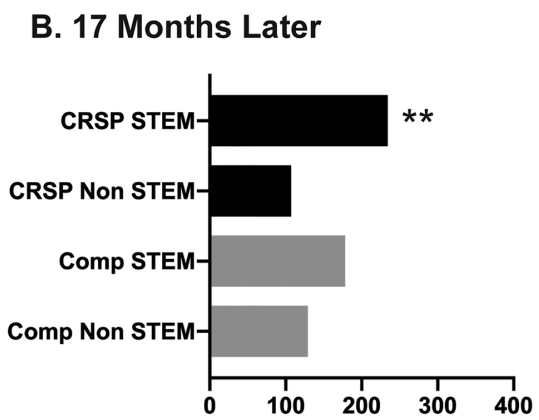

Total number of Students (2014-2017)

FIGURE 2. STEM retention for CRSP and comparison group students. (A) Numbers of students from CRSP ( $n=490$, dark gray bars) and comparison ( $n=490$, light gray bars) groups in STEM and non-STEM disciplines at the start of the program for each cohort: Y1 (2014), Y2 (2015), and Y3 (2016). (B) Same as A, except that the student identification numbers from each group were queried for STEM disciplines 17 months later. The number of students remaining in the database (i.e., still at CUNY) was as follows: CRSP (341/490) and comparison group (307/490). **, $p=0.006$ using Fisher's exact test.

difficulty imposed by such employment was "significant," while $34 \%$ said that employment made it only "a little more difficult to concentrate on CRSP and classroom work." Forty percent of those who worked said that their outside employment had no impact on CRSP and classroom work. Only $17 \%$ of respondents indicated that the CRSP stipend enabled them to reduce the number of hours they would have normally worked.

Focus Groups with Program Directors and Faculty Mentors We conducted focus groups with program directors and faculty mentors at six colleges during the 2017-2018 academic year. All of the program directors expressed strong positive sentiments about CRSP and discussed the value of the student research experience, the positive impact of the stipend, and the role of mentoring in student success. CRSP is usually the largest single research program at their colleges, and several directors noted that it has introduced research into the broader college culture. As one director stated, "Without it, students would not know about research. Word has gotten out. Students walk around and see the posters. They talk to each other and ask their professors about it. It gets the conversation started about research."

In our focus groups with faculty mentors, the most frequently mentioned aspect of the program, according to a key word search, was its yearlong duration. Nine mentors stressed the time frame. As one mentor framed it, "Students are often discouraged by their first encounters with scientific research, because they lack the skills to engage with real science. But CRSP allows us to meet regularly with them over a year and to take them through the process of dissecting scientific papers. It encourages faculty members to take time to nurture students." Another told us, "In a year, you really get to know students and help them get results. Getting results in three months is difficult."

The second most frequently mentioned aspect of the program, cited by six mentors, was the $\$ 5000$ stipend. Not only does the stipend alleviate some financial pressure on students, the mentors explained, it also leads students to see that their research is taken seriously. "The stipend is helping students because it is making them commit," one mentor said. "That commitment is great because it helps them and it helps us. They stay with us longer. Sometimes, a student starts research with us and then leaves after one semester because they have to go on to something else, including a job. The money the students receive makes them accountable." Other impacts of the program mentors cited included self-confidence (six mentions), maturity (five mentions), student dedication (five mentions), and independence (five mentions).

Mentors made clear that the program had a positive impact on them as well, both in terms of the satisfaction they derive from seeing their students succeed and in the contributions to their own careers. Eleven mentors told us that it had helped them professionally. Three of them, for instance, reported that the experience contributed to their ability to receive NSF funding. An additional three mentioned that CRSP students had helped them gather data on projects they used to apply for other funding. A positive impact on mentors helps make the program sustainable.

\section{DISCUSSION}

To evaluate the contribution of CRSP to student success, we developed a mixed-methods assessment including an analysis of objective outcomes data, surveys of student participants, interviews with college-based directors, and focus groups with faculty mentors. Our aims were both formative and summative. Student surveys and discussions with directors and mentors enabled us to understand, from the perspective of participants, whether and in what ways CRSP was having an impact and where there might be need for changes in focus and practice. Our summative evaluation enabled us to draw conclusions about the overall effect of the program.

We believe our longitudinal assessment of objective student outcomes-graduation, STEM retention, and transfer patterns - to be the largest of its kind involving a yearlong research program with associate's degree students. Results were encouraging. A significantly higher percentage of students (59\%) who enrolled in the program graduated within 1,2 , or 3 years relative to members of the comparison group (50\%). CRSP students were also significantly more likely to remain in a STEM field. These outcomes confirm the value of the CRSP structure: a yearlong research program that provides students with dedicated mentors, a laboratory-based research project, regular 


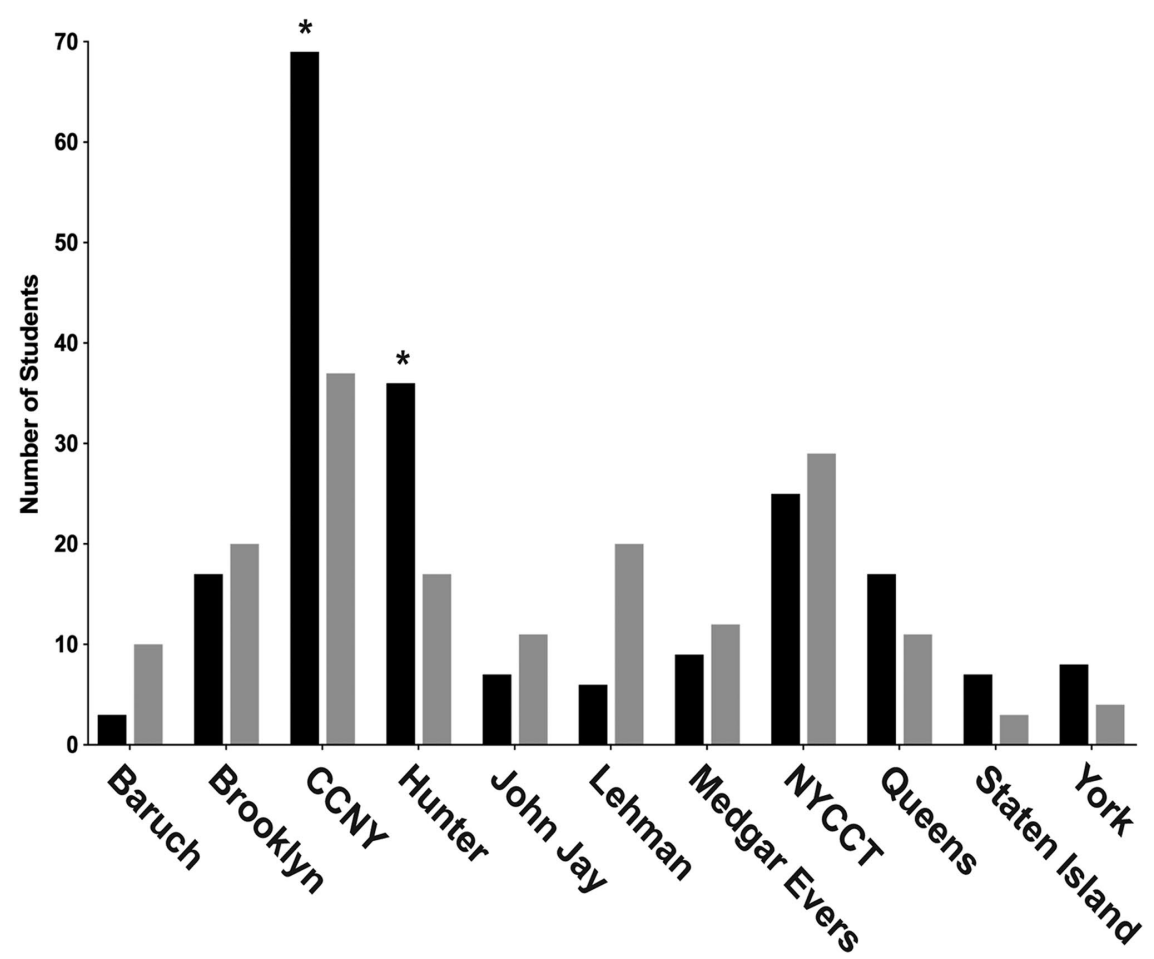

FIGURE 3. Impact of CRSP participation on school choice. The graph shows the number of students who transferred from a CUNY community college to a CUNY 4-year school the semester following the end of the program for each of the three cohorts under study (Y1, Fall 2015; Y2, Fall 2016; Y3, Fall 2016). $n=204$ CRSP students and 174 comparison group students. For the CRSP students, significant transfer to CCNY and Hunter College was observed compared with comparison group students. *, $p \leq 0.05$.

college-based programming, a stipend, and a symposium to present their work before a large audience.

In focus groups, mentors encouraged a holistic view of the program and of the student experience. Student success, they stressed, includes not only the objective measures of academic advancement but the development of qualities such as persistence, confidence, and a scholarly outlook. When asked to name the greatest strength of the program, mentors most frequently cited its yearlong duration. Over the course of a year, mentors are able to expose students to the full scope of the scientific research process. They can work with students through failed experiments and inculcate the need for persistence. They teach students how to read, digest, and write scientific papers. Students develop self-confidence and mastery as they work through such tasks and when they present their work to college-based audiences at the CRSP symposium and to broader audiences at regional and national scientific conferences. The relationship between mentors and students constitutes a form of social capital, a relationship that facilitates students' adjustment to college life, their sense of identification with their area of research, and their increasing identification as aspiring scientists (Coleman, 1988).

Student responses on surveys revealed the essential role played by mentors. Clear majorities of students felt that mentors helped them to develop both scientific skills and knowledge and a sense of self-confidence. Self-confidence as a researcher is itself an important form of social capital (Garner et al., 2018), and a cornerstone of self-confidence results from direct recruitment by mentors. Nearly three-quarters of CRSP students (72\%) told us that they felt as if their mentors cared about them as individuals, and the importance of this finding is illustrated by Great Jobs, Great Lives: The Gallup-Purdue Index Report (Gallup-Purdue University, 2014), which indicates how important being cared for is for students in their future. Likewise, a sense of belonging is essential to students' engagement in and outside the classroom and to retention in STEM disciplines (Eagan et al., 2013). A sense of belonging is especially important for the retention of women and URMs in STEM disciplines (Cheryan et al., 2009; Good et al., 2012; Brainard and Carlin, 2013).

These results suggest that yearlong structured programs similar to CRSP have transformative potential. Fewer than one-third of CRSP students who took our survey told us that, before entry into the program, they enjoyed going to college or felt comfortable at their colleges. Most students told us their experiences in college consisted of going to classes with little further engagement. After entry into the program, on the other hand, a sizable majority of students reported that they enjoyed attending college and that they experienced a wider sense of belonging to and connection with their colleges.

We attribute these shifts in student belonging at least in part to the mentor-student relationship (Weidman, 1989). As mentors expose students to research methods and laboratory practices, they are coaching them to be self-directed and to take ownership of their research projects (Carpi et al., 2016), and they are demonstrating for students what it is like to be a working scientist (Hunter et al., 2006). They are cultivating growth mind-sets and identification with their disciplines. Mentors are also available for students when they need other kinds of support. In focus groups, mentors told us that they help students learn to balance research, classroom, and work obligations. They also told us that they have become aware of the personal and family burdens affecting their students. When students are able to share these difficulties, mentors felt, it increases their self-confidence, their perception that someone cares for them, and their sense of belonging in college. Shanahan (2018) confirms that a mentor's social and emotional support is often critical to a student's success, especially among those who are economically disadvantaged or are URMs. She found that, for students of color, "having a faculty mentor whom they could trust was deemed more important than any other aspect of participating in research" (Shanahan, 2018, p. 49).

Mentors emphasized what they saw as an essential impact of the program: CRSP helps students develop identities as aspiring scholars and scientists. After a year in the program, students have a project to write about when applying to 4-year colleges, to graduate programs, or for employment (also see 


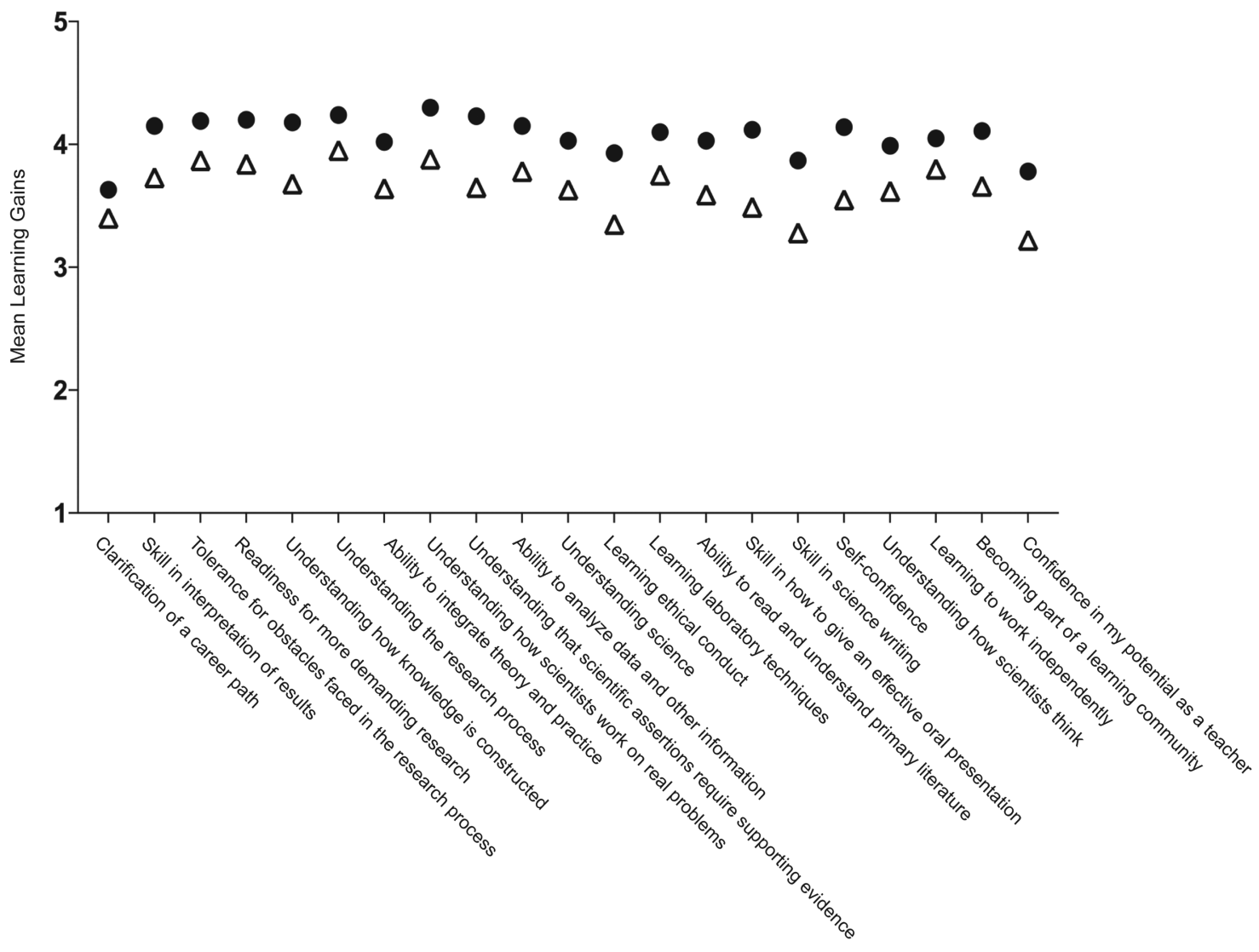

FIGURE 4. Student self-reported learning gains using the SURE survey. Learning gains on a scale of 1 (no or small gain) to 5 (very large gain) for 26 different learning attributes of the research experience. CRSP students ( $n=94$; filled circles) and all students who submitted the survey nationwide in 2017 ( $n=2252$; open triangles).

Russell et al., 2007). The student research experience also enables mentors to write letters of recommendation that describe students' skills and abilities in much more detail than they could with a student they have gotten to know only through the classroom. Many students, especially URMs, experience difficulties bridging their personal life identities with an academic identity, and such difficulties can lead to internal conflict (Shanahan, 2018). Mentors explained to us that writing letters of recommendation that incorporate a yearlong project helps to affirm students' identities as scientists, and the letter itself is an important form of social capital. The emphasis on letter writing that arose in our focus groups contrasts with Hunter et al.'s study (2006), in which they discovered a low level of interest among faculty mentors in résumé building and letter writing for their students. In every one of the six focus groups we conducted, however, mentors were quick to emphasize the importance of letter writing for students' social capital (Coleman, 1988; Garner et al., 2018; Shanahan, 2018).

This contribution to a scientific identity and the ability of mentors to craft extensive letters for their students may account for one of the most intriguing results of our analysis. CRSP students transferred to 4-year colleges at rates similar to their counterparts in the comparison group, but they were much more likely to attend the CUNY colleges that receive the highest levels of research funding (CCNY and Hunter). Among students who transferred to colleges external to
CUNY, CRSP students were significantly more likely to attend an R1 university.

Despite the success of the CRSP program in promoting STEM retention and graduation, our students still face several challenges. One of the persistent difficulties is the tendency of students to work long hours and, often, to juggle more than one outside job. Approximately two-thirds of CRSP students were engaged in external employment, and approximately $60 \%$ of survey respondents who worked told us that such employment made it more difficult to concentrate on course work and other academic responsibilities. Mentors and directors frequently mentioned outside work as an all-but-inevitable burden that students must factor into their research and course work loads.

Mentors try to help students cope with demands of work and, when possible, to use the CRSP stipend to reduce work hours or to give up at least one of their outside jobs. Though the stipend was intended to allay students' need to work, mentors and directors acknowledged that the demands of home life (including care for children or other dependent relatives) and the cost of living in one of the world's most expensive cities make it unlikely that more students will be able to forgo work altogether. It is a testimony to their tenacity (Dweck et al., 2014) and to the encouragement they receive from mentors that most CRSP students are able to take on a research program, complete their course work, and continue working while still meeting the requirements for graduation. 
In conclusion, our results show that 1-year mentored research experiences have a positive impact on associate's degree student success at CUNY. Although the CUNY system is unique in many ways, we note from the work of the CCURI (Hewlett, 2018) that many community colleges have faculty who engage in research with their students, suggesting that the benefits we are observing are broadly scalable.

\section{ACKNOWLEDGMENTS}

We thank the Office of the Mayor of New York for generous support of the CRSP. We also thank Michael Shields for help with institutional databases, Michael Guy for advice on statistics, Rimi Dhar for administrative assistance, and all of the college-based directors and mentors for making the program successful. Thanks also to Sarah Bonner, Anthony Carpi, Nancy Hensel, and Dan McCloskey for critical comments on the article.

\section{REFERENCES}

American Association of Community Colleges. (2017). Enrollment trend. Data Points, 5(3), 1.

Bock, H. A. H. J. (2018). Undergraduate research: Changing the culture at community colleges. Scholarship and Practice of Undergraduate Research, 1(4), 49-50.

Brainard, S. G., \& Carlin, L. (2013). A six-year longitudinal study of undergraduate women in engineering and science. Journal of Engineering Education, 87(4), 369-375. doi: 10.1002/j.2168-9830.1998.tb00367.x

Brown, D. R., Higgins, T. B., \& Coggins, P. (2007). The increasing presence of undergraduate research in two-year colleges. CUR Quarterly, 28(2), 24-28.

Caplan, A. J., \& MacLachlan, E. S. (2014). An overview of undergraduate research in the CUNY community college system. In Hensel, N. H., \& Cejda, B. D. (Eds.), Tapping the potential of all: Undergraduate research at community colleges (pp. 9-16). Washington, DC: Council on Undergraduate Research.

Carpi, A., Ronan, D. M., Falconer, H. M., \& Lents, N. H. (2016). Cultivating minority scientists: Undergraduate research increases self-efficacy and career ambitions for underrepresented students in STEM. Journal of Research in Science Teaching, 54(2), 169-194. doi: 10.1002/tea.21341

Cheryan, S., Plaut, V. C., Davies, P. G., \& Steele, C. M. (2009). Ambient belonging: How stereotypical cues impact gender participation in computer science. Journal of Personality and Social Psychology, 97(6), 1045-1060. doi: $10.1037 / a 0016239$

Cochran, W. G., \& Rubin, D. B. (1973). Controlling bias in observational studies: A review. Sankhyā: The Indian Journal of Statistics, Series A (19612002), 35(4), 417-446.

Coleman, J. S. (1988). Social capital in the creation of human capital. American Journal of Sociology, 94, S95-S120.

Dehejia, R., \& Wahba, S. (2002). Propensity score-matching methods for nonexperimental causal studies. Review of Economics and Statistics, 84(1), 151-161.

Dweck, C. S., Walton, G. M., \& Cohen, G. L. (2014). Academic tenacity, mindsets and skills that promote long-term learning. Bill and Melinda Gates Foundation. Retrieved from https://ed.stanford.edu/sites/default/files/ manual/dweck-walton-cohen-2014.pdf

Eagan, M. K., Jr., Hurtado, S., Chang, M. J., Garcia, G. A., Herrera, F. A., \& Garibay, J. C. (2013). Making a difference in science education: The impact of undergraduate research programs. American Educational Research Journal, 50(4), 683-713. doi: 10.3102/0002831213482038

Fechheimer, M., Webber, K., \& Kleiber, P. B. (2011). How well do undergraduate research programs promote engagement and success of students? CBELife Sciences Education, 10(2), 156-163. doi: 10.1187/cbe.10-10-0130

Gallup-Purdue University. (2014). Great jobs, great lives: The 2014 GallupPurdue index report. Retrieved October 4, 2018, from www.gallup.com/ file/services/176768/GallupPurduelndex_Report_2014.pdf

Garner, P. W., Mahatmya, D., Jones, R. M., \& Davis, S. N. (2018). Undergraduate research mentoring relationships: A mechanism for developing social capital for underrepresented students. In Vandermaas-Peeler, M., Miller, P. C.,
\& Moore, J. L. (Eds.), Excellence in mentoring undergraduate research (pp. 77-103). Washington, DC: Council on Undergraduate Research.

Good, C., Rattan, A., \& Dweck, C. S. (2012). Why do women opt out? Sense of belonging and women's representation in mathematics. Journal of Personality and Social Psychology, 102(4), 700-717. doi: 10.1037/a0026659

Hewlett, J. A. (2018). Broadening participation in undergraduate research experiences (UREs): The expanding role of the community college. CBELife Sciences Education, 17(3), es9. doi: 10.1187/cbe.17-11-0238

Hunter, A.-B., Laursen, S. L., \& Seymour, E. (2006). Becoming a scientist: The role of undergraduate research in students' cognitive personal and professional development. Science Education, 91, 36-74.

King, G., Nielsen, R., Coberley, C., Pope, J. E., \& Wells, A. (2011). Comparative effectiveness of matching methods for causal inference. https://scholar google.com/scholar?q=King+Gary+Nielsen+Richard+Coberley+Carter +Pope+James+and+Wells+Aaron+.+2011.+Comparative+effectiveness +of+matching+methods+for+causal+inference

Kuh, G. D. (2008). High-impact educational practices: What they are, who has access to them and why they matter. Association of American Colleges \& Universities.

Lopatto, D. (2004). Survey of Undergraduate Research Experiences (SURE): First findings. Cell Biology Education, 3(4), 270-277. doi: 10.1187/cbe.0407-0045

Lopatto, D. (2007). Undergraduate research experiences support science career decisions and active learning. CBE-Life Sciences Education, 6(4), 297-306. doi: 10.1187/cbe.07-06-0039

Lopatto, D., Alvarez, C., Barnard, D., Chandrasekaran, C., Chung, H. M., Du, C., ... \& Elgin, S. C. (2008). Undergraduate research. Genomics Education Partnership. Science, 322(5902), 684-685. doi: 10.1126/science.1165351

Lunt, M. (2014). Selecting an appropriate caliper can be essential for achieving good balance with propensity score matching. American Journal of Epidemiology, 179(2), 226-235. doi: 10.1093/aje/kwt212

Nagda, B. A., Gregerman, S. R., Joindes, J., Von Hippel, W., \& Lerner, J. S (1998). Undergraduate student-faculty research partnerships affect student retention. Review of Higher Education, 22(10), 55-72.

National Center for Education Statistics. (2017). Graduation rate from first institution attended within 150 percent of normal time for first-time, full-time degree/certificate-seeking students at 2-year postsecondary institutions, by race/ethnicity, sex, and control of institution: Selected cohort entry years, 2000 through 2013. Digest of Education Statistics. Washington, DC: Integrated Postsecondary Education Data System, Institute of Education Sciences, U.S. Department of Education. Retrieved January 31, 2019, from https://nces.ed.gov/programs/digest/d17/tables/dt17_326.20.asp

Ritchie, L. (2016). Fostering self efficacy in higher education students. New York: Palgrave Teaching and Learning, Palgrave Macmillan.

Rodenbusch, S. E., Hernandez, P. R., Simmons, S. L., \& Dolan, E. L. (2016). Early engagement in course-based research increases graduation rates and completion of science, engineering, and mathematics degrees CBE-Life Sciences Education, 15(2), ar20. doi: 10.1187/cbe.16-03-0117

Rosenbaum, P. R., \& Rubin, D. B. (1983). The central role of the propensity score in observational studies for causal effects. Biometrika, 70(1), 41-55. doi: 10.1093/biomet/70.1.41

Rosenbaum, P. R., \& Rubin, D. B. (1985). Constructing a control group using multivariate matched sampling methods that incorporate the propensity score. American Statistician, 39(1), 33-38. doi: 10.1080/00031305.1985 10479383

Russell, S. H., Hancock, M. P., \& McCullough, J. (2007). The pipeline. Benefits of undergraduate research experiences. Science, 316(5824), 548-549. doi: $10.1126 /$ science. 1140384

Shanahan, J. O. (2018). Mentoring strategies that support underrepresented students in undergraduate research. In Vandermaas-Peeler, M., Miller, P. C., \& Moore, J. L. (Eds.), Excellence in mentoring undergraduate research. Washington, DC: Council on Undergraduate Research.

Weidman, J. (1989). Undergraduate socialization: A conceptual approach. In Smart, J. C. (Ed.), Handbook of theory and research (vol. 5, pp. 289-322). New York: Agathon Press.

Wilson, D., Jones, D., Bocell, F., Crawford, J., Kim, M. J., Veilleux, N., ... \& Plett, M. (2015). Belonging and academic engagement among undergraduate STEM students: A multi-institutional study. Research in Higher Education, 56(7), 750-776. 